\title{
SPRAY COOLING TRAJECTORY ANGLE IMPACT UPON HEAT FLUX USING A STRAIGHT FINNED ENHANCED SURFACE
}

\author{
Eric A. Silk ${ }^{\dagger}$ \\ Thermal Engineering Branch \\ NASA Goddard Space Flight Center \\ Greenbelt, MD 20771 \\ Tel:(301) 286-5534 Fax:(301) 286-1704 \\ Eric.A.Silk@nasa.gov \\ Jungho Kim \\ Mechanical Engineering Department \\ University of Maryland \\ College Park, MD 20742 \\ Tel:(301) 405-5437 Fax:(301) 314-9477 \\ kimjh@eng.umd.edu \\ Ken Kiger \\ Mechanical Engineering Department \\ University of Maryland \\ College Park, MD 20742 \\ Tel:(301) 405- 5245 Fax:(301) 314-9477 \\ kkiger@eng.umd.edu
}

HT2005-72634

\section{ABSTRACT}

Experiments were conducted to study the effects of spray trajectory angles upon heat flux for flat and enhanced surface spray cooling. The surface enhancement consisted of straight fins machined on the top surface of a copper heater block. Spray cooling curves were obtained with the straight fin surface aligned both parallel (axial) and perpendicular (transverse) to the spray axis. Measurements were also obtained on a flat surface heater block for comparison purposes. Each copper block had a cross-sectional area of $2.0 \mathrm{~cm}^{2}$. A $2 \times 2$ nozzle array was used with PF-5060 as the working fluid. Thermal performance data was obtained under nominally degassed (chamber pressure of $41.4 \mathrm{kPa}$ ) conditions. Results show that the maximum $\mathrm{CHF}$ in all cases was attained for a trajectory angle of $30^{\circ}$ from the surface normal. Furthermore, trajectory angles applied to straight finned surfaces can have a critical heat flux (CHF) enhancement as much as $75 \%$ (heat flux value of $140 \mathrm{~W} / \mathrm{cm}^{2}$ ) relative to the vertical spray orientation for the analogous flat surface case under nominally degassed conditions.

Keywords: Enhancement, Spray Cooling, Finned Surfaces, Heat Transfer, Trajectory Spray

\section{INTRODUCTION}

Numerous research efforts have been undertaken to gain a better understanding of the general phenomena and critical parameters associated with the spray cooling heat transfer process. Previous studies have parametrically examined the effect of secondary gas atomizers vs. pressure atomizers $[17,19]$, mass flux of ejected fluid $[4,20]$, spray velocity $[2,16]$, surface impact velocity $[2,5,15]$, surface roughness $[1,11,16,17]$, ejected fluid temperature, chamber environmental conditions, and spray footprint optimization on the effective heat flux across the surface [10]. Other topics researched to date include the effect of surfactant addition [12,13], and secondary nucleation $[9,14,17]$.

This work is a continuation of the enhanced surface study by Silk et al. [18], with emphasis on straight fins as the featured surface structure geometry. The objective of the current work is to examine the effects of spray trajectory angle upon heat flux for a flat and enhanced surface (specifically straight fins) when using a multi-nozzle array.

Previous studies dealing with spray trajectory angles have emphasized the spray cone and its relation to the heater surface from either a vertical or horizontal position. The work by Mudawar and Estes [10] examined heat flux as a function of cone angle and nozzle height for a given flow rate. The heater surface tested was square $\left(12.7 \times 12.7 \mathrm{~mm}^{2}\right)$ while the nozzle used had a circular spray footprint. Working fluids used were FC-72 and FC-87. The authors determined that CHF was a function of volumetric flow distribution on the heater surface. The optimum CHF was attained by inscribing the heater surface with the perimeter of the spray cone footprint.

In the work by Kearns et al. [7], spray cooling of a row of heaters was performed inside a narrow channel. A total of nine 
heaters was used each with an area of $38.1 \mathrm{~mm}^{2}$. The channel had length, width and height dimensions of $400 \mathrm{~mm}, 265 \mathrm{~mm}$, and $255 \mathrm{~mm}$ respectively. Fluid was sprayed into the channel at one end by a single full cone nozzle with a cone angle of $55^{\circ}$. The configuration was designed to simulate confinement conditions inside an actual circuit board. The working fluid used was PF-5060 at $101 \mathrm{kPa}$. The maximum dissipation $(60 \mathrm{~W})$ occurred with the lead heater closest to the nozzle. The minimum $(20 \mathrm{~W})$ occurred with the heater farthest away. The authors concluded that this was due to the proximity of the leading heater relative to the nozzle as well as the impingement angle on its leading edge.

Most studies that have examined enhanced surfaces have done so primarily from the perspective of surface roughness. Sehmbey et al. [17] gives an overview of spray cooling and provides a comparison of its effectiveness when using liquid and secondary gas atomizers (air used as the secondary gas). Heat flux was measured and presented for both techniques. Both the heat flux and the convection coefficient were found to have comparable values for both atomizer types. The authors concluded that the most important parameters affecting heat transfer are the fluid properties, spray velocity and surface conditions. It was also found that the heat transfer coefficient increased with the use of smooth surfaces $\left(R_{a}<0.1 \mu \mathrm{m}\right)$ for gas atomized sprays, while the opposite trend was observed for liquid atomized sprays.

Pais et al. [11] studied the effects of surface roughness on heat transfer when using spray cooling. The surface roughness values studied were 22,14 and $0.3 \mu \mathrm{m}$. The heat exchange surface was copper with a projected area of $1 \mathrm{~cm}^{2}$. An air-assist atomizing nozzle was used with deionized water as the working fluid. Tests were conducted at a nozzle height of $23 \mathrm{~mm}$. Tests were run to the CHF value for all surface tolerances. It was found that the $0.3 \mu \mathrm{m}$ rough surface achieved the highest heat fluxes of the group with a peak heat flux of $1250 \mathrm{~W} / \mathrm{cm}^{2}$. Furthermore, the onset of nucleate boiling was experienced at lower superheat values for this roughness. The authors attributed the heat transfer enhancement to early bubble departure from the surface and nucleate boiling. The authors also concluded that secondary nucleation has a primary role as a heat transfer mechanism only if the surface finish is smooth.

Studies utilizing straight finned enhanced surfaces have been performed in both pool boiling and spray cooling. Chien and Webb [3] investigated the effects of structured tunnel dimensions on nucleate boiling convection coefficients for heat fluxes ranging between 2 and $70 \mathrm{~kW} / \mathrm{m}^{2}$. Tests were performed on a $19.1 \mathrm{~mm}$ diameter horizontal tube using R-11 and R-123 as working fluids. Tunnel pitch, height, width, and base radius were the primary dimensions reviewed. The authors found that fins smaller than the height of $0.9 \mathrm{~mm}$ experienced significant increases in the convection coefficient as the fin count increased from 1378 fins $/ \mathrm{m}$ to 1575 fins $/ \mathrm{m}$. They also found that using straight fins helped to increase evaporation by retaining more liquid. Increasing fin height had little effect upon the convection coefficient. Fin pitch was also seen as having little effect.
The enhanced surface spray cooling investigation by Silk et. al. [18] consisted of a surface structure survey entailing pyramids, cubic pin fins and straight fins of similar feature geometry size and pitch. Tests were conducted using PF-5060 at nominally degassed (41.4 kPa) and gassy (101 kPa using $\mathrm{N}_{2}$ gas) conditions. Each of the surface structures tested showed an increase in heat flux relative to the analogous flat surface case for both degassed and gassy conditions. The straight fins attained the maximum values for all the surfaces tested. The degassed case showed a straight fin heat flux enhancement of $55 \%$ (nominal value of $126 \mathrm{~W} / \mathrm{cm}^{2}$ ) and the gassy increased by $48 \%$ (nominal value of $156 \mathrm{~W} / \mathrm{cm}^{2}$ ). The authors attributed these increases to fluid surface management.

The present work investigates heat transfer enhancement at various spray angles. This study may result in techniques leading to higher heat fluxes at comparable thermodynamic conditions and spray characteristics. Droplet velocity has been shown as being the dominant spray characteristic impacting heat flux [2] for sprays normal to the heater surface. An angular trajectory would reduce the vertical component magnitude with respect to a trajectory angle normal to the heater surface, and may result in a reduction in heat flux corresponding to the velocity reduction. The current study shows that the heat flux can increase with angular spray trajectories.

\section{NOMENCLATURE}

A

$P$

$R_{a}$

TC

We

$d$

e

$h$

$k$

$l$

$p$

$\theta$

$\mu$

\section{SUBSCRIPTS}

$i$
$H$

$L_{s}$

$T$

V

$X$

$q^{\prime \prime}$

$u$

$x$

$\Gamma$

$\gamma$

$\sigma$

$k$

concentric ring

conductivity

structure height

distance between successive structures

pressure

Surface Roughness

temperature

thermocouple

droplet velocity

structure feature dimension

Weber number

diameter

error

convection coefficient

conductivity

nozzle height above heater surface

pitch

heat flux per unit area

uncertainty

weighted volume flux for concentric ring

spray trajectory angle

straight fin planar orientation angle

viscosity

surface tension thermocouple distance 


$\begin{array}{ll}l & \text { liquid } \\ \max & \text { maximum } \\ q & \text { heat flux } \\ \text { surf } & \text { surface } \\ T & \text { temperature } \\ v & \text { vapor } \\ x & \text { thermocouple distance } \\ 32 & \text { Sauter Mean Diameter } \\ o & \text { spray nozzle orifice }\end{array}$

\section{TEST SETUP AND PROCEDURE}

The experiments were conducted using a closed fluid loop system. The test rig (schematic shown in Fig. 1) consists of an environmental test chamber, liquid pump, flow meter, microfilter and a condenser. Chamber temperature and pressure were measured via a T-type thermocouple and a pressure sensor. Temperature and pressure sensors were also placed in the liquid line upstream of the nozzle for fluid and supply line temperature and pressure measurement.

Each of the test heaters were made of oxygen free copper with a uniform undercoat of $2.54 \mu \mathrm{m}$ nickel and $1.27 \mu \mathrm{m}$ topsurface coat of gold. Heat was supplied to the test article using a $500 \mathrm{~W}$ cartridge heater. The test article was placed within the interior of the chamber, but was separated from the excess

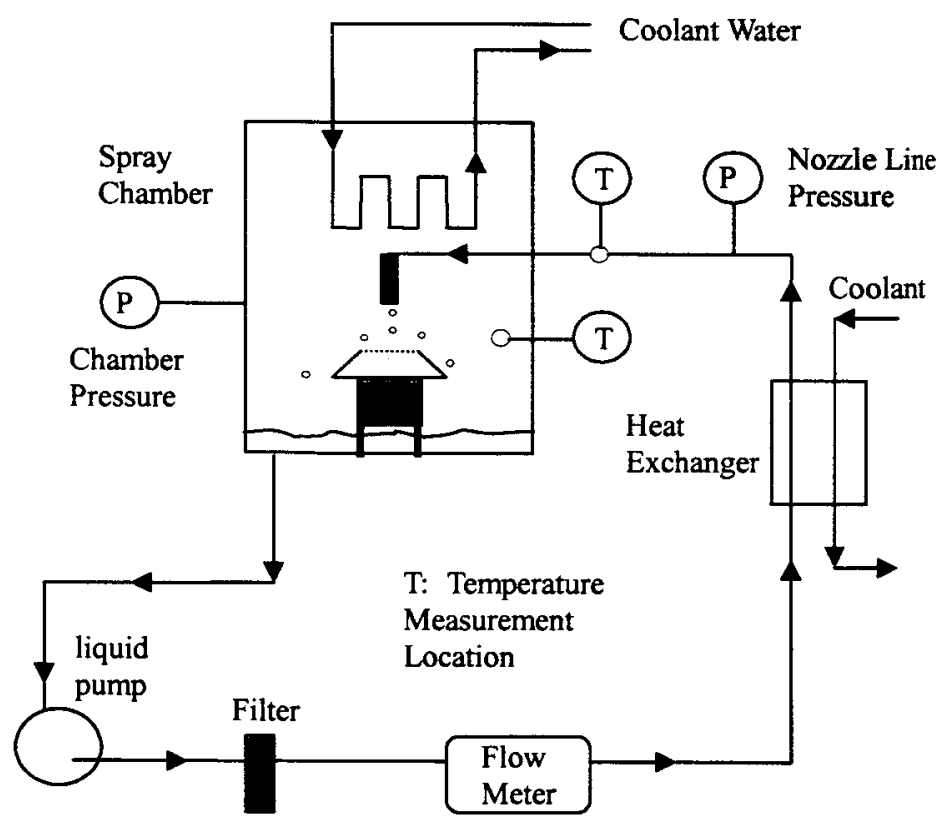

Fig. 1 Spray Cooling Test Rig Configuration

liquid by an enclosure consisting of polycarbonate housing and an alumina bisque ceramic top flange. The upper section of the copper blocks was epoxied to the ceramic flange. Temperature measurements in the copper blocks were sampled via five Ttype thermocouples mounted in the upper neck of each block (shown in Fig. 2). Assuming steady state 1-D conduction through the upper neck of the block, the heat flux was calculated using Fourier's Law of conduction. The surface temperature was determined via linear extrapolation using TC1 and TC2.

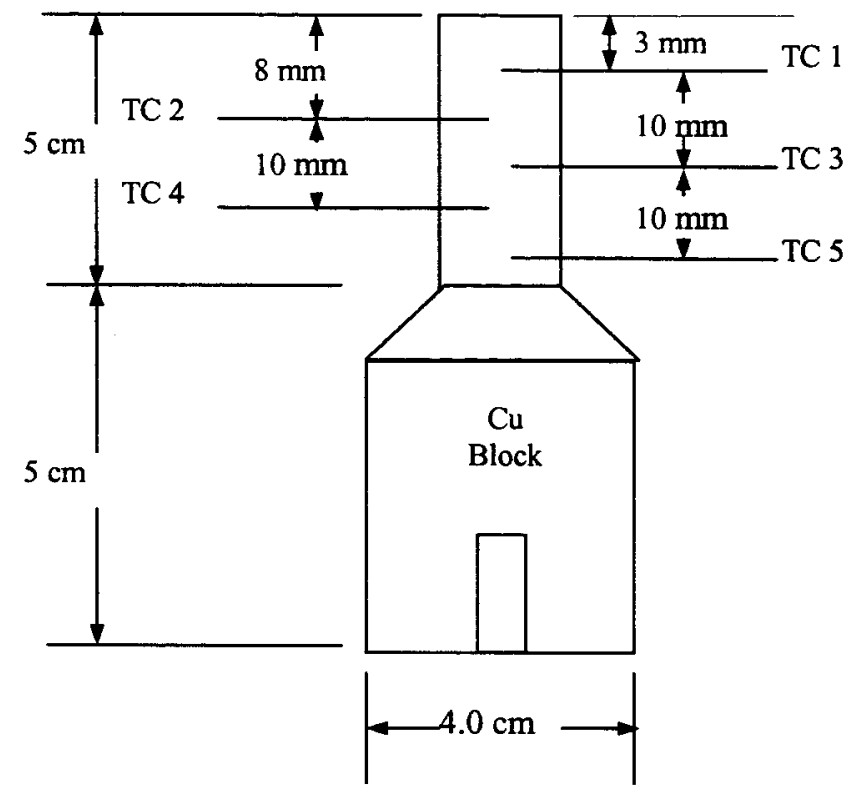

Fig. 2 Copper block schematic with TC locations (not to scale)

\begin{tabular}{|c|c|c|c|c|}
\hline Section & Area $\left(\mathrm{cm}^{2}\right)$ & Area $(\%)$ & $\begin{array}{c}\text { Vol. Flux } \\
\left(\mathrm{m}^{3} / \mathrm{m}^{2} \mathbf{s}\right)\end{array}$ & $\Gamma_{i}$ \\
\hline $\mathrm{A}_{1}$ & 0.33 & 17.5 & 0.026 & 2.0 \\
\hline $\mathrm{A}_{2}$ & 0.38 & 20 & 0.024 & 1.8 \\
\hline $\mathrm{A}_{3}$ & 0.54 & 28.5 & 0.007 & 0.6 \\
\hline $\mathrm{A}_{4}$ & 0.64 & 34 & 0.005 & 0.4 \\
\hline
\end{tabular}

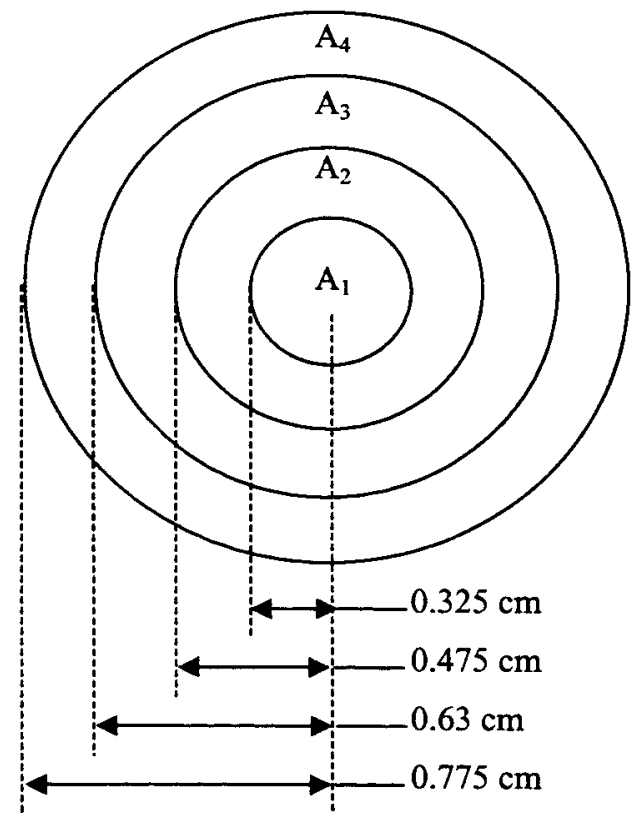

Fig. 3 Spray Uniformity Test Schematic (not to scale) 
Prior to each test, the spray chamber and fluid loop were charged with PF-5060. For the degassed case, a vacuum was repeatedly applied to the chamber until a pressure of $41.4 \mathrm{kPa}$ (470 ppm gas concentration) was reached. The chamber was allowed to attain equilibrium prior to conducting the tests.

All tests were run at constant chamber pressure, liquid flow rate $(200 \mathrm{ml} / \mathrm{min})$ and constant nozzle height above the heater surface. Heat was supplied to the cartridge heater in increments of $10 \mathrm{~W}$ using a programmable power supply. Steady state was achieved at each power level before application of the next successive heat load. Upon dry-out (detected by a rapid increase in surface temperature and a rapid decrease in heat flux), power to the cartridge heater was shut-off.

A Parker Hannifin prototype spray nozzle was used for each of the tests. The nozzle consists of a $2 \times 2$ spray cone array. Prior to heat flux testing, the spray nozzle uniformity was measured using several stainless steel tubes of varying inner diameters, a graduated cylinder, and a stopwatch. The largest tube had an inner diameter approximately the same diameter as the heated surface. Size, local volume flux between concentric cylinders, and the local volume flux between concentric cylinders normalized by the average volume flux over the entire heater surface $(\Gamma)$ is shown in Fig. 3. A $\Gamma$ value of unity indicates that the local volume flux is identical to the total volume flux averaged across the entire heater surface. The outer ring $\left(A_{4}\right)$ is shown as captures $60 \%$ less volume flux than the average area value. The volume flux is shown to gradually increase towards the center of the heater region. The center ring $\left(A_{1}\right)$ which encompasses only $17.5 \%$ of the heater area in question has twice as much volume flux as the total for the entire area. Given the volume flux variation throughout the concentric rings, the spray may be effectively considered a non-uniform center biased spray for the current nozzle height and heater area. Spray characteristics were not investigated during this study.

Three trajectory angles $(\theta)$ were tested in this study. These are $0^{\circ}$ (vertical), $30^{\circ}$, and $45^{\circ}$. The angles were taken using the centerline axis of the spray nozzle manifold relative to the $0^{\circ}$ orientation (see Fig. 4). The nozzle manifold height $(l)$ was held constant for each of the tests. Delrin spacers were fabricated

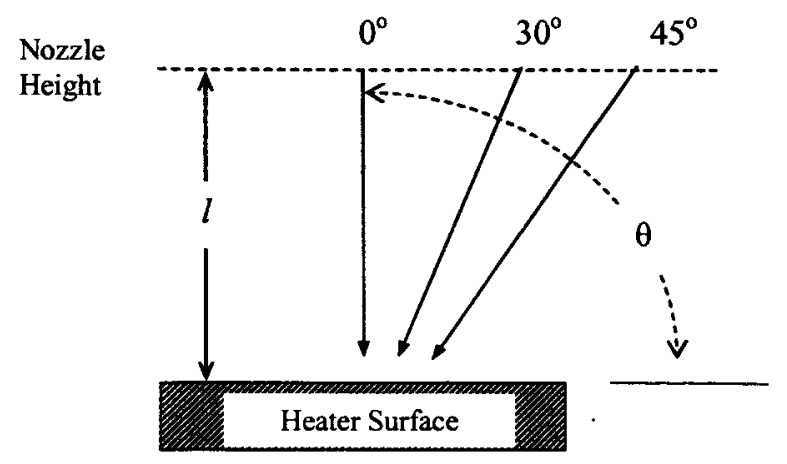

Fig. 4 Centerline axis trajectory survey angles and used in the positioning of the nozzle relative to the heater surface for repeatability.

$\mathrm{X}$

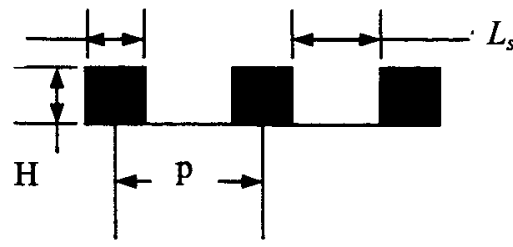

Cross Sectional View for Straight Fins

Fig. 5 Enhanced Surface Geometry

\begin{tabular}{|c|c|c|c|c|}
\hline Surface & $\begin{array}{c}\mathbf{p} \\
(\mathrm{mm})\end{array}$ & $\begin{array}{c}\mathbf{X} \\
(\mathrm{mm})\end{array}$ & $\begin{array}{c}\mathbf{L}_{\mathbf{s}} \\
(\mathrm{mm})\end{array}$ & $\begin{array}{c}\mathbf{H} \\
(\mathrm{mm})\end{array}$ \\
\hline Flat Surface (1f) & 0 & 0 & 0 & 0 \\
\hline Straight Fins (1s) & 2 & 1 & 1 & 1 \\
\hline
\end{tabular}

Table 1 Enhanced Surface Geometry Summary

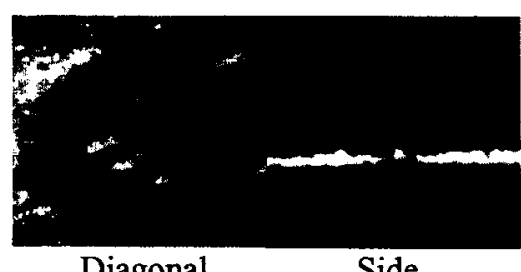

Diagonal

Side

Fig. 6 Straight Fin CCD Images

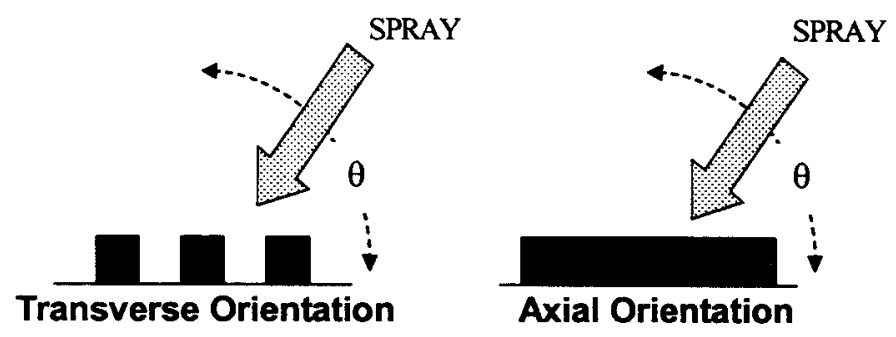

SIDE VIEW

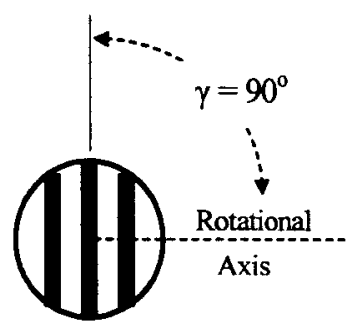

Transverse Orientation

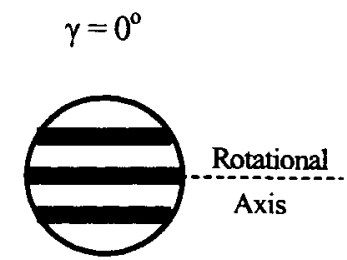

Axial Orientation
TOP VIEW

Fig. 7 Straight Fin Orientations 
Inherent to this study is the surface structure of the enhanced heater block used for tests. The dimensions of the straight fin surface (1s) are shown on Fig. 5 and detailed in Table 1. Photographs of the enhanced surface are shown in Fig. 6. When spraying onto the straight fin surface at an angle other than the $0^{\circ}$ position, the structures' planar angle relative to the spray rotational axis $(\gamma)$ presents two cases (and ultimately bounds) for the present study. The two cases are the transverse $\left(\gamma=90^{\circ}\right)$ and axial orientations $\left(\gamma=0^{\circ}\right)$ as shown in Fig. 7. Studies were performed with the straight fin surface at both of the orientations.

\section{MEASUREMENT UNCERTAINTY}

The primary quantity of interest for these experiments is the heat flux. The heat flux calculation has three sources of error. These are the conductivity, the thermocouple locations, and the error in the temperature measured. The conductivity value used was $389 \mathrm{~W} / \mathrm{m} \mathrm{K}$ with $1 \%$ error. The data acquisition unit used for thermocouple measurements had a signal to temperature conversion accuracy of $\pm 0.1{ }^{\circ} \mathrm{C}$. The error in the thermocouple location was determined to be $\pm 0.56 \mathrm{~mm}$. Equation 1 was used to calculate the error for the heat flux values reported.

$$
u_{q}= \pm \sqrt{\left(\frac{\partial q}{\partial k} \cdot e_{k}\right)^{2}+\left(\frac{\partial q}{\partial T} \cdot e_{T}\right)^{2}+\left(\frac{\partial q}{\partial x} \cdot e_{x}\right)^{2}}
$$

The uncertainty in the heat flux was determined to be $3.4 \%$ at $80 \mathrm{~W} / \mathrm{cm}^{2}$ which corresponds to the smallest CHF for all the cases tested. Pressure values recorded had an uncertainty of \pm 3 $\mathrm{kPa}$. Flow meter measurements were attributed an error of \pm 1 $\mathrm{ml} / \mathrm{min}$.

\section{RESULTS AND DISCUSSION}

Heat flux as a function of the surface temperature and spray trajectory angle for the flat surface (1f) is shown in Fig. 8. Heat flux as a function of the surface temperature and spray trajectory angle for the straight fin surface in the transverse $\left(\gamma=90^{\circ}\right)$ and axial orientation $\left(\gamma=0^{\circ}\right)$ are respectively shown in Figs. 9 and 10. The heat flux is based on the projected area of $2.0 \mathrm{~cm}^{2}$, as opposed to the actual total surface area exposed to the fluid.

Fig. 8 shows that the heat flux increases as the trajectory angle is varied from the $\theta=0^{\circ}$ position. The maximum CHF of $96 \mathrm{~W} / \mathrm{cm}^{2}\left(20 \%\right.$ enhancement relative to $\left.\theta=0^{\circ}\right)$ occurred for the $30^{\circ}$ case while the $45^{\circ}$ case attained CHF at a slightly lower value of $92 \mathrm{~W} / \mathrm{cm}^{2}$. The maximum surface temperature reached for both non-vertical cases was approximately $67^{\circ} \mathrm{C}$. The $\theta=45^{\circ}$ case showed very good agreement with the $\theta=0^{\circ}$ case in the single phase convection regime $\left(\mathrm{T}_{\text {surf }} \leq 55^{\circ} \mathrm{C}\right)$ whereas the $\theta=30^{\circ}$ case held slightly higher heat fluxes. Multiphase effects become more pronounced in the intermediate regime $\left(55^{\circ} \mathrm{C} \leq\right.$
$\mathrm{T}_{\text {surf }} \leq 64{ }^{\circ} \mathrm{C}$ ) with the $45^{\circ}$ case increasing to equivalent heat flux performance relative to the $30^{\circ}$ case. The curves then separate in the high heat flux regime $\left(\mathrm{T}_{\text {surf }}>64{ }^{\circ} \mathrm{C}\right)$ as $\mathrm{CHF}$ is approached.

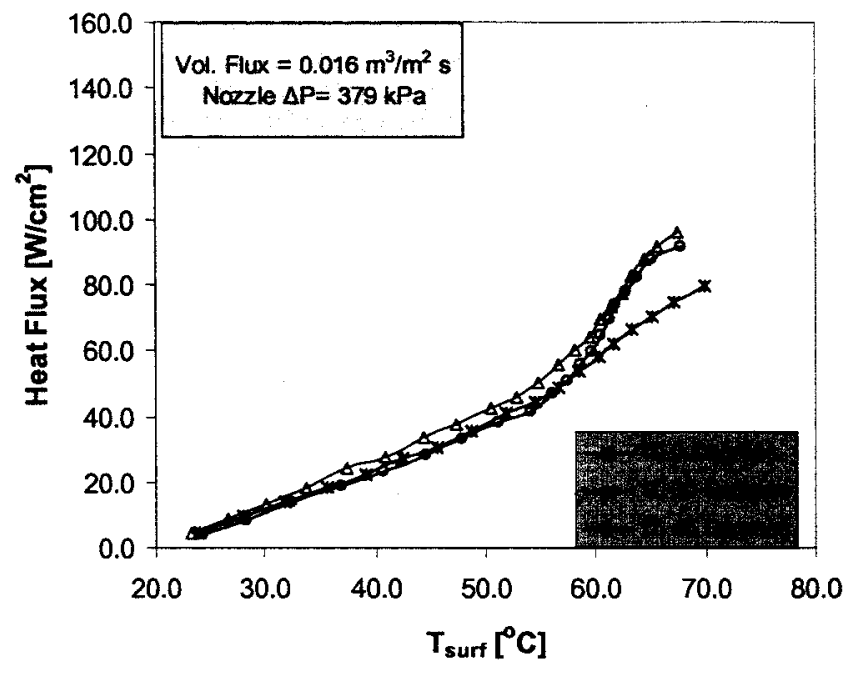

Fig. 8 Heat Flux as a function of surface temperature and Trajectory angle for flat surface

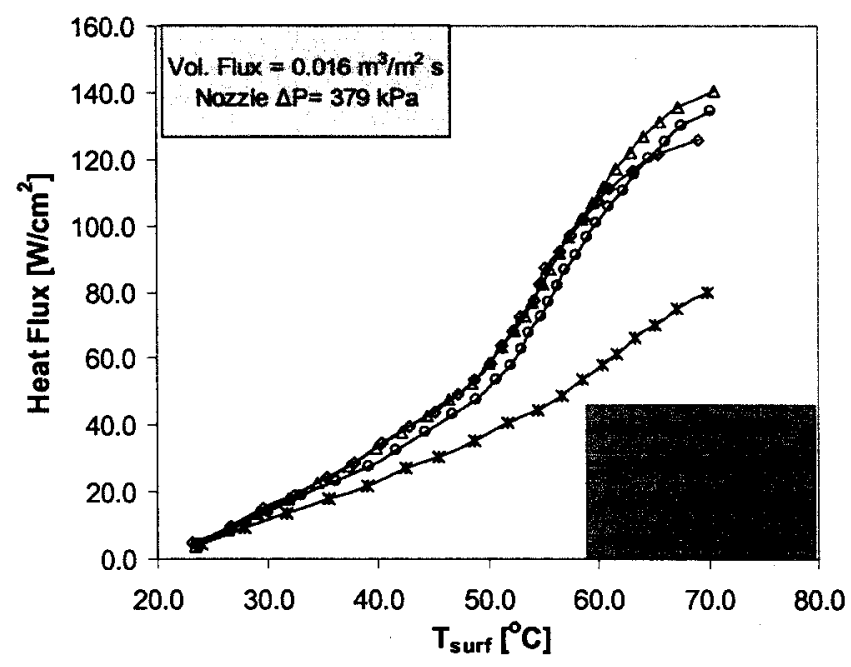

Fig. 9 Heat Flux as a function of surface temperature and Trajectory angle for Transverse straight fins

In the straight fin $\gamma=90^{\circ}$ study (shown in Fig. 9), the maximum CHF $\left(140 \mathrm{~W} / \mathrm{cm}^{2}\right)$ also occurred for $\theta=30^{\circ}$. This gave a heat flux enhancement of $11 \%$ relative to the $\theta=0^{\circ}$ straight fin case and $75 \%$ relative to the $\theta=0^{\circ}$ flat surface case. The $45^{\circ}$ case had a CHF value $\left(135 \mathrm{~W} / \mathrm{cm}^{2}\right)$ slightly lower than the $30^{\circ}$ case. The heat fluxes for the $\theta=0^{\circ}$ and $30^{\circ}$ straight fin cases agreed throughout the surface temperature domain until entering the high heat flux regime $\left(\mathrm{T}_{\text {surf }}>60^{\circ} \mathrm{C}\right)$. The $\theta=45^{\circ}$ case had slightly lower heat flux values than the $0^{\circ}$ and $30^{\circ}$ cases throughout the entire surface temperature domain until 
transitioning to the high heat flux regime. In the approach to $\mathrm{CHF}$, the heat flux performance increased beyond that of the $\theta=0^{\circ}$ case.

The straight fin $\gamma=0^{\circ}$ study (shown in Fig. 10) also showed the maximum CHF $\left(132 \mathrm{~W} / \mathrm{cm}^{2}\right)$ occurring for the $\theta=30^{\circ}$ case. The heat flux enhancement relative to the $\theta=0^{\circ}$ straight fin and flat surface cases was $5 \%$ and $65 \%$ respectively. CHF for the

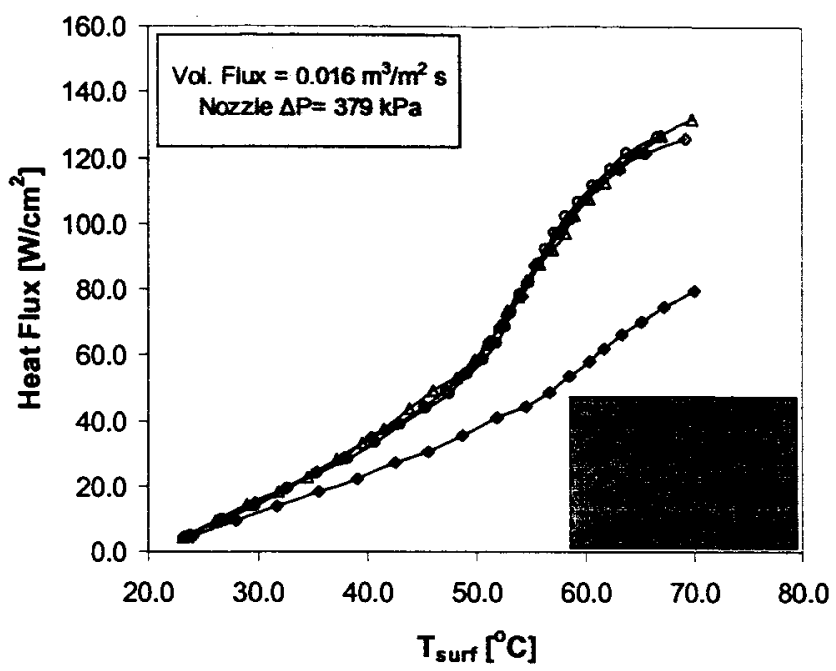

Fig. 10 Heat Flux as a function of surface temperature and Trajectory angle for Axial straight fins

$\theta=45^{\circ}$ case was $126 \mathrm{~W} / \mathrm{cm}^{2}$. The heat flux curves for the $\theta=0^{\circ}$, $30^{\circ}$, and $45^{\circ}$ cases agreed well until just prior to CHF. The maximum surface temperature attained for the $45^{\circ}$ case $\left(\mathrm{T}_{\text {surf }}\right.$ $=67^{\circ} \mathrm{C}$ ) was slightly lower than that of the $0^{\circ}$ and $30^{\circ}$ cases. Table 2 gives a summary of CHF, maximum surface temperature, and CHF percent enhancement relative to the flat surface for each of the cases. The Table 2 data is arranged in descending order with respect to the heat flux. The straight fins outperformed the flat surface for each $\gamma$ and $\theta$ orientation. The $\gamma=90^{\circ}$ cases for the straight fins had higher CHF values than the $\gamma=0^{\circ}$ cases. Furthermore, each set of experiments showed that the $\theta=30^{\circ}$ case attained the highest heat flux. Table 3 shows the. The maximum enhancement of $75 \%$ corresponded with the

\begin{tabular}{|c|c|c|c|c|c|}
\hline Surface & $\gamma$ & $\theta$ & $q_{\left(W / \mathrm{cm}^{2}\right)}^{q^{\prime \prime}}$ & $\begin{array}{c}\text { CHF } \\
\text { Enhancement } \\
\text { (relative to } \\
\text { Flat Surface } \\
\text { CHF at } 0^{\circ} \text { ) }\end{array}$ & $\begin{array}{l}T_{\max } \\
\left({ }^{\circ} \mathrm{C}\right)\end{array}$ \\
\hline $1 \mathrm{~s}$ & $90^{\circ}$ & $30^{\circ}$ & 140 & $75 \%$ & 70.5 \\
\hline $1 \mathrm{~s}$ & $90^{\circ}$ & $45^{\circ}$ & 135 & $69 \%$ & 70.3 \\
\hline ls & $0^{\circ}$ & $30^{\circ}$ & 132 & $65 \%$ & 69.8 \\
\hline $1 \mathrm{~s}$ & $0^{\circ}$ & $45^{\circ}$ & 126 & $58 \%$ & 66.7 \\
\hline $1 \mathrm{~s}$ & $\ldots$ & $0^{\circ}$ & 126 & $58 \%$ & 69.1 \\
\hline 1f & $\ldots$ & $30^{\circ}$ & 96 & $20 \%$ & 67.4 \\
\hline lf & $-\ldots$ & $45^{\circ}$ & 92 & $15 \%$ & 67.8 \\
\hline $1 \mathrm{f}$ & $-\cdots$ & $0^{\circ}$ & 80 & $0 \%$ & 70.0 \\
\hline
\end{tabular}

Table 2 Summary of Trajectory Study Test Data maximum heat flux for the $\gamma=90^{\circ}, \theta=30^{\circ}$ case.

The study by Chen et. al. [2] showed that the droplet velocity (as opposed to the spray density or droplet diameter) had the largest impact upon heat transfer. Due to the density of the spray at the flow rate tested, spray characterization measurements detailing droplet size and velocity were not performed. However, assuming negligible velocity losses during travel to the heater surface, the droplet dispersion velocity at the orifice $\left(\mathrm{V}_{\mathrm{o}}\right)$ may be considered an approximation of the droplet impact velocity. This velocity can be determined using the relation developed by Ghodbane and Holman [5]. The final form for the velocity relation is shown in equation $2 . V_{\text {tube }}$ is the upstream velocity of the fluid in the tubing. The pressure drop across the nozzle is $\Delta P$.

$$
V_{o}=\left[V_{\text {rube }}^{2}+\frac{2 \Delta P}{\rho_{l}}-\frac{12 \sigma}{\rho d_{32}}\right]^{1 / 2}
$$

The Sauter Mean Diameter (SMD) was calculated using equation $3[4,8]$.

$$
\frac{d_{32}}{d_{o}}=3.07\left(\frac{\rho_{v}^{0.5} \Delta P d_{o}^{1.5}}{\sigma^{0.5} \mu_{l}}\right)^{-0.259}
$$

The We (shown in equation 4) also is of particular importance. The We (which incorporates a second order velocity term) is the ratio of the inertia to surface tension forces. It is a metric for the spreading force upon droplet impact for the sprays' stagnation flow field. In standard $\left(\theta=0^{\circ}\right.$ orientation) spray cooling configurations the value corresponds with the heat flux (i.e. as the We increases, the heat flux increases to a critical value). The spreading force is felt normal to the heat exchange surface. In the case of angular trajectory sprays, the velocity vector must be decomposed whereby the vertical component (normal to the heater surface) is used in the We calculation.

$$
W e=\frac{\rho_{l} V_{o}^{2} d_{32}}{\sigma}
$$

Table 3 gives a listing of the dispersion velocity and We for each $\theta$ angle tested. The vertical velocity components decreased with increasing $\theta$ as expected. The general trending correspondence for the We is inverted since the $\theta=30^{\circ}$ and $45^{\circ}$ orientations outperformed the $0^{\circ}$ orientation (with exception to the straight fin $\gamma=0^{\circ}, \theta=45^{\circ}$ case).

One feature of the center weighted nozzle array used was that it created excess liquid in the center of the heat exchange surface for the $\theta=0^{\circ}$ orientation. This was witnessed for both the 
flat and straight fin surfaces. The straight fin structures themselves exacerbated the pooling and helped to make the excess liquid line more pronounced. As heat loads were

\begin{tabular}{|c|c|c|c|}
\hline$\theta$ & $\begin{array}{c}\text { Vertical } \\
\text { Velocity } \\
(\mathrm{m} / \mathrm{s})\end{array}$ & $\begin{array}{c}\text { Horizontal } \\
\text { Velocity } \\
(\mathrm{m} / \mathrm{s})\end{array}$ & We \\
\hline $0^{\circ}$ & 21.2 & 0.0 & 1796 \\
\hline $30^{\circ}$ & 18.4 & 10.6 & 1348 \\
\hline $45^{\circ}$ & 15.0 & 15.0 & 898 \\
\hline
\end{tabular}

Table 3 Dispersion Velocity and We for variable $\theta$ values

gradually increased towards $\mathrm{CHF}$, the liquid line receded slowly. In the flat surface case, it was only slightly noticeable at CHF. However, in the case of the straight fins, it never fully receded. For the angular trajectory orientations $\left(\theta=30^{\circ}\right.$ and $\left.45^{\circ}\right)$, the excess liquid line was not noticeable throughout any of the heat flux regimes. This along with the increased pressure coefficient indicates that the angular trajectories help promote better fluid spreading across the heater surface and ultimately better heat transfer. This is instituted by the sweeping motion of the spray droplets' horizontal velocity components. Based on the experimental data, it appears that instituting a sweeping motion, while maintaining a dominant vertical velocity component fosters higher heat fluxes than the case of a dominant sweeping velocity. This is witnessed in the comparison of the results for the $\theta=30^{\circ}$ and $45^{\circ}$ orientations for each case. However, further investigation is required.

The straight fin surface exposed to angular trajectories creates two unique flow scenarios with special considerations. When examining fluid motion upon the surface, both the $\gamma=0^{\circ}$ and $\gamma=90^{\circ}$ (broad-crested weir) case may be consider open channel flows. For the $\theta=0^{\circ}$ orientation testing, fluid was witnessed jetting out of the structure channels. This channel jetting motion was also witnessed in the $\gamma=0^{\circ}$ case (applied to both $\theta=30^{\circ}$ and $45^{\circ}$ ). However, it was negligible in the $\gamma=90^{\circ}$ case for both $\theta=30^{\circ}$ and $45^{\circ}$. Upon droplet impact on the surface, the non-evaporated bulk fluid must conform to the surface structures and the channel paths in its motion. This is inertia driven. As such, excess liquid in the $\gamma=90^{\circ}$ case undergoes deflection by the structures and redirection down the channel. This translates into lower channel velocities in relation to the $\gamma=0^{\circ}$ case. The lower channel velocities allow for fuller nucleation and ultimately higher heat fluxes. The higher channel velocities inherent to the $\gamma=0^{\circ}$ cases suppresses nucleation more and lowers the heat flux.

\section{SUMMARY AND CONCLUSIONS}

Spray cooling heat flux measurements were performed on a straight fin enhanced surface and a flat surface using PF-5060. Tests were performed under nominally degassed $(41.4 \mathrm{kPa})$ environmental conditions. The volumetric flux $\left(0.016 \mathrm{~m}^{3} / \mathrm{m}^{2} \mathrm{~s}\right)$ and nozzle height from the surface $(17 \mathrm{~mm})$ were held constant for all the tests.
The maximum heat flux attained occurred with the straight fin surface (1s) at $\gamma=90^{\circ}, \theta=30^{\circ}$. The explicit value for the heat flux was $140 \mathrm{~W} / \mathrm{cm}^{2}$ giving an enhancement of $75 \%$ relative to the flat surface case at the vertical spray orientation $\left(\theta=0^{\circ}\right)$.

The We decreased with increasing angular trajectory $(\theta)$. Both angular trajectories of $\theta=30^{\circ}$ and $45^{\circ}$ attained higher CHF values than the $\theta=0^{\circ}$ case.

The maximum heat flux occurred at a spray trajectory of $\theta=30^{\circ}$ for each of the case studies performed. This angle presented a dominant vertical velocity component in comparison to the sweeping (horizontal) velocity component.

Application of the angular trajectories eliminated liquid pooling on both the straight fin and flat surfaces.

The $\gamma=0^{\circ}$ case for the straight fin angular trajectories held higher channel velocities than the $\gamma=90^{\circ}$. This corresponded to a higher level of nucleate suppression and lower heat fluxes.

\section{ACKNOWLEDGMENTS}

This research was supported by the Thermal Management group of the Laboratory for Physical Sciences and funded by the Laser Risk Reduction Program (LRRP) at the NASA Goddard Space Flight Center. Dr. Jungho Kim and Dr. Kenneth Kiger would like to acknowledge the generous support of the Office of Naval Research under contract number N000140410315 directed by Dr. Mark Spector. The authors would like to thank Dr. Paul Boudreaux, for his assistance, as well as J.B. Dotellis and Lester Lorentz for their support in machining the copper test articles and their surfaces. Special thanks is also given to Rick Fedorchak, Richard Freburger and Mark Kobel of NASA Goddard Space Flight Center for their test support as well as Parker Hannifin's Gas Turbine Fluid Systems Division (GTFSD) for supplying the spray nozzle.

\section{REFERENCES}

[1] Bernadin, J.D., and Mudawar, I., 1999, "The Leidenfrost Point: Experimental Study and Asessment of Existing Models," Journal of Heat Transfer, Vol. 121, pp. 894-903

[2] Chen, R-H., Chow, L., and Navedo, J., 2002, "Effects of spray characteristics on critical heat flux in subcooled water spray cooling," International Journal of Heat and Mass Transfer, Vol. 45, pp. 4033-4043

[3] Chien, L.H., and Webb, R.L., 1998a, "A Parametric Study of Nucleate Boiling on Structured Surfaces, Part I: Effect of Tunnel Dimensions," Journal of Heat Transfer, Vol. 120, pp. 1042-1048

[4] Estes, K.A., and Mudawar, I., 1995, "Correlation of Sauter mean diameter and critical heat flux for spray cooling of small surfaces," International Journal of Heat and Mass Transfer, Vol.38, No.16, pp. 2985-2996 
